\title{
AS CONTRIBUIC̄̃̃ES DO PIBID PARA O DESENVOLVIMENTO DOS SABERES DOCENTES: A EXPERIÊNCIA DA LICENCIATURA EM CIÊNCIAS NATURAIS, UNIVERSIDADE DE BRASÍLIA
}

\author{
DELANO MOODY SIMÕES DA SILVA ${ }^{*}$ \\ https://orcid.org/0000-0002-6784-6161 \\ VIVIANE APARECIDA DA SILVA FALCOMER ${ }^{* *}$ \\ https://orcid.org/0000-0002-5056-8265 \\ FRANCO DE SALLES PORTO ${ }^{1 * *}$ \\ https://orcid.org/0000-0002-0931-4968
}

RESUMO: A formação do professor deve ser pensada e construída dentro da sua profissão, com estratégias de formação que proporcionem aos futuros professores a inserção no seu ambiente de trabalho e o desenvolvimento/mobilização de saberes relacionados à carreira docente. Nessa perspectiva, o Programa Institucional de Bolsas de Iniciação à Docência (PIBID) tem contribuído para os processos de formação de professores em diversas áreas. O objetivo desse estudo foi, a partir dos relatórios entregues pelos alunos bolsistas do PIBID, discutir as contribuições desse programa para o desenvolvimento e mobilização dos saberes docentes nos alunos participantes do subprojeto de Ciências Naturais (Universidade de Brasília). Nossos resultados indicam que os bolsistas participantes do PIBID mobilizam e desenvolvem saberes relacionados à profissão docente, indicando que essa proposta tende a romper com um modelo de formação aplicacionista do conhecimento, respeitando e reconhecendo a escola e seus professores como colaboradores e parceiros no processo de formação.

Palavras-Chave: Formação de professores; Saberes docentes; Carreira docente.

LAS CONTRIBUCIONES DEL PIBID AL DESARROLLO DE LOS SABERES DOCENTES: LA EXPEPERIENCIA DE LA LICENCIATURA EM LAS CIENCIAS NATURALES (UNIVERSIDAD DE BRASILIA).

RESUMEN: La formación del maestro debe ser pensada y construida dentro de su profesión, con estrategias de formación que proporcionen a los futuros maestros la inserción en el ambiente de trabajo y el desarrollo/movilización de saberes relacionados a la carrera docente. En esta perspectiva, el "Programa Institucional de Bolsas de Iniciação à Docência"

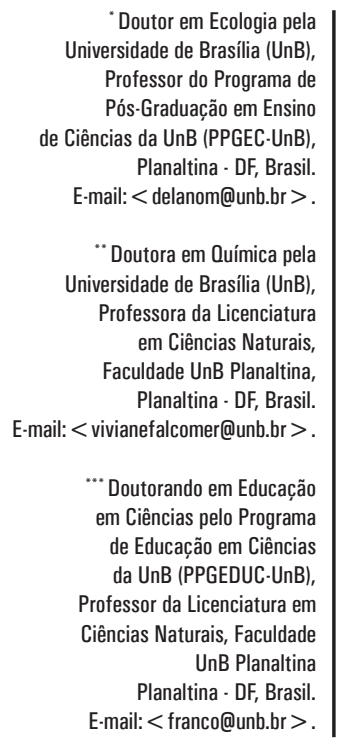

versidade de Brasília (UnB),

Professor do Programa de

Pós-Graduação em Ensino Planaltina - DF, Brasil $<$ delanom@unb.br > versidade de Brasília (UnB), em Ciências Naturais, culdade UnB Planaltina, Planaltina - DF, Brasil.

** Doutorando em Educação Ciências pelo Programa de Educação em Ciências da UnB (PPGEDUC-UnB), Ciências Naturais, Faculdade Planaltina - DF, Brasil. E-mail: < franco@unb.br >.

${ }^{1}$ Faculdade UnB Planaltina, Planaltina, DF - Brasil. 
(PIBID) ha contribuido para los procesos de formación de maestros en diversas áreas del conocimiento. El objetivo de este estudio fue, a partir de los informes entregados por los alumnos becantes del PIBID, discutir las contribuciones de este programa para el desarrollo y movilización de los saberes docentes en los alumnos participantes del subproyecto de las Ciencias Naturales (Universidad de Brasília). Nuestros resultados indican que los becarios participantes del PIBID movilizan y desarrollan saberes relacionados a la profesión docente, indicando que esta propuesta tiende a romper con un modelo de formación aplicacionista del conocimiento, respetando y reconociendo la escuela y sus maestros como colaboradores y compañeros en el proceso de formación.

Palabras clave: Formación de maestros; Saberes Docentes; Carrera Docente.

\section{THE CONTRIBUTIONS OF PIBID TO THE DEVELOPMENT OF TEACHING KNOWLEDGES: THE EXPERIENCE OF NATURAL SCIENCES GRADUATION (UNIVERSITY OF BRASILIA).}

ABSTRACT: Teacher education must be thought and built inside its own profession, with training strategies that provide to the future teachers their insertion in workplaces and the development/mobilization of knowledges related to the teaching career. In this perspective, the "Programa Institucional de Bolsas de Iniciação à Docência" (PIBID) has contributed to teacher education in several areas. The goal of this study was to discuss the contribution of PIBID to development and mobilization of teaching knowledges in students that take part of the natural sciences subproject (University of Brasilia). Our results show that the students of natural science subproject mobilize and develop knowledges related the teaching profession indicating that propose tends to break with the training model that exclusively applies knowledge, respecting, and recognizing the school and their teachers as collaborators and partners in the training processes.

Keywords: Teacher education; Teaching knowledges; Teaching career. 
As contribuições do PIBID para o desenvolvimento dos saberes docentes:

A experiência da Licenciatura em Ciências Naturais, Universidade de Brasília

\section{INTRODUÇÃO}

Ao se pensar na formação de um profissional, de uma forma bem simplista, deve-se levar em consideração os conhecimentos necessários para atuação na profissão e como estes são aplicados. De modo geral, o primeiro grupo de conhecimentos são identificados como teóricos e o segundo como práticos. Dessa forma se espera que toda a profissão tenha um conjunto de conhecimentos teóricos que a caracterizam e atividades ou procedimentos práticos que são relacionadas a ela. Porém identificar esses conhecimentos, que muitas vezes são de naturezas diferentes e relacioná-los com a prática da profissão nem sempre é uma tarefa fácil. Em se tratando da docência os desafios são maiores ainda, pois além desses saberes teóricos e práticos, existem outros de natureza vivencial que são somente construídos na ação (NUNES, 2001).

Para Nóvoa (2009) a preparação do profissional docente deve ser construída dentro da profissão, levando em consideração vários aspectos como o público para o qual esse educador vai atuar, sua história de vida e as relações dele com os demais profissionais. Dessa forma, pensar na formação docente sem levar em consideração também no ambiente de atuação destes, a escola, e nas relações que se estabelecem nesse espaço, é pensar numa formação fragmentada. Tardif (2014) afirma que para se compreender os saberes do professor devemos sempre levar em consideração a sua relação com o trabalho na escola e na sala de aula. Além disso, observar e conviver com professores mais experientes contribuem para a construção de novos saberes (SHULMAN, 1986; TARDIF, 2014). A constituição desses saberes pelo professor, ajuda-o a construir a sua identidade com a profissão (PIMENTA, 1996) e a ele também se tornar um produtor destes (CAMPOS; DINIZ, 2001), adquiridos a partir da prática e no confronto com as condições do cotidiano da escola (NUNES, 2001).

Nessa perspectiva, os cursos de formação de professores deveriam promover e valorizar os momentos de contato com o cotidiano escolar, a prática docente e a interação com profissionais da educação. Porém, apesar das inúmeras mudanças que os cursos de licenciaturas vem passando nos últimos anos (GATTI; BARRETO, 2009; GATTI, BARRETO; ANDRÉ, 2011), inclusive com o aumento do número de horas de estágio supervisionado de ensino (DIAS-DA-SILVA, 2005; AYRES; SELLES, 2012), ainda temos poucos espaços nos cursos para a vivência de experiências na escola e o trabalho compartilhado com professores da educação básica, pois muitos cursos ainda formam professores baseados na perspectiva da racionalidade técnica, no conhecido modelo "3+1" (SANTOS; SCHNETZLER, 2003; GATTI, 2010; MASSENA; MONTEIRO, 2011; CHAVES; TERRAZAN, 2015).

Em dezembro de 2007 a Coordenação de Aperfeiçoamento de Pessoal de Nível Superior (Capes) criou o Programa Institucional de Bolsas de Iniciação à Docência (PIBID), que dentre vários objetivos propostos possibilitou ampliar os espaços e o tempo de formação de professores, contribuindo para que pudessem construir e mobilizar seus saberes no seu local de atuação, a escola. Com isso, reconhecendo a escola como um espaço de formação e o professor da educação básica como um parceiro desse processo (SCHEIBE, 2010; OLIVEIRA; BARBOSA, 2013; TANCREDINI, 2013), viabilizando o envolvimento de bolsistas 
e professores no cotidiano das atividades escolares, permitindo que os primeiros possam ir além dos saberes adquiridos no âmbito da formação universitária, pois convivem e vivenciam com os profissionais de ensino e sua realidade, mobilizando e desenvolvendo novos saberes validando-os no fazer cotidiano.

O PIBID de Ciências Naturais da Universidade de Brasília começou suas atividades no edital CAPES 01/2011, tendo início em julho de 2011 e finalizando suas atividades em fevereiro de 2018 com o término do edital. Ao longo desses seis anos participaram do projeto mais de 50 alunos, 8 professores e seis escolas.

Diante desse cenário possibilitado pelo PIBID, o objetivo desse trabalho é a partir dos relatórios anuais entregues pelos alunos bolsistas do programa, discutir as contribuições desse programa para o desenvolvimento e mobilização dos saberes docentes nos alunos participantes do subprojeto de Ciências Naturais (Faculdade UnB Planaltina, Universidade de Brasília).

\section{OS SABERES DOCENTES NA FORMAC̦ÃO DE PROFESSORES}

Nas décadas de 1980 e 1990 os pesquisadores na área de formação de professores buscaram identificar um corpo de conhecimentos que são necessários para a prática docente e que esses, ao mesmo tempo, permitissem a identificação e caracterização da profissão (NUNES, 2001). Para Shulman (1986) eles estariam agrupados em três categorias de conhecimentos, da disciplina a ser estudada, pedagógico do conteúdo e curricular. O domínio sobre estes estaria relacionado às temáticas em si que seriam ensinados, às particularidades desenvolvidas pelo professor para melhor compreensão dos estudantes sobre os assuntos específicos abordados e às adequações necessárias para cada segmento respectivamente. Apesar de não indicar como um conhecimento específico, o autor reconhece o papel da prática na aquisição desses (learning from experience), indicando que somente a partir da prática, ou seja, da sua atuação como docente, o professor irá aprender a lidar com as surpresas e incertezas da sala de aula.

Vários outros autores apresentaram propostas de tipificação ou classificação desses conhecimentos, ou como são considerados atualmente saberes docentes (PÓRLAN et al., 1997; GAUTHIER et al., 1998; PIMENTA, 1999; TARDIF, 2014). Apesar das palavras saberes e conhecimentos não serem exatamente sinônimos, alguns autores não fazem distinção quando abordam o tema (CAMPOS; DINIZ, 2001), pois consideram que o significado conceitual é o mesmo por possuírem “os mesmos ingredientes fundamentais, mas não suficientes: de saber, de saber-fazer e de saber-ser" (PUENTES et al., 2009, p. 182).

Independentemente da classificação todos os autores concordam que ser professor não é apenas dominar conteúdos a serem ensinados ou ter "o dom", mas é necessário também aprender sobre ser professor (GAUTHIER et al., 1998). Existe uma tendência no entendimento que esses saberes sofrem grande influência pela prática, pela experiência (PÓRLAN et al., 1997; GAUTHIER et al., 1998; TARDIF, 2014), mas que essa não é a única fonte, pois o ensino não é uma atividade exclusivamente prática e intuitiva, sendo que a experiência deve dialogar com os outros saberes (SARMENTO, 1994). O equilíbrio e diálogo entre esses saberes são os grandes desafios no processo de formação de professores, pois 
tender mais para um lado ou para outro pode formar professores que "dominam" muitos conteúdos mas não conhecem a realidade da escola ou que atuam por intuição, mas sem a fundamentação para suas ações.

Dentro dessa concepção, Tardif (2014) coloca que o saber dos professores é plural, oriundo de fontes e espaços diversos e podem ser organizados em quatro saberes: os da formação profissional, os disciplinares, os curriculares e os experienciais. Os saberes da formação profissional estão relacionados à ciência da educação, filosofia e teorias pedagógicas. Os disciplinares são relacionados às disciplinas que o professor irá ministrar (ex. Biologia, Química e Física). Os curriculares são relativos aos currículos das secretarias de educação, planejamentos e estratégias de ensino. Finalmente os experienciais que são os saberes oriundos da prática docente (TARDIF, 2014).

Outros autores fizeram proposições diferentes, detalhando e ampliando os saberes docentes (GAUTHIER et al., 1998) ou condensando-os (PIMENTA, 1999). Em todas as proposições o saber da experiência é considerado como fundamental, pois é constituído por outros saberes, oriundo da prática do cotidiano e validado por ela (CUNHA, 2007). Nesse trabalho fundamentamos nossa pesquisa na proposição de Tardif (2014), pois contempla os eixos formativos de nosso curso de forma menos fragmentada.

\section{A INFLUÊNCIA DO PIBID NA FORMAC̣ÃO DE PROFESSORES}

Segundo dados disponibilizados no portal da CAPES (CAPES, 2018) em 2014 haviam 313 instituições e 90.000 bolsistas participando do programa. Diante desses números, fica evidente o impacto que um programa dessa natureza pode ter sobre os cursos de formação de professores nas Instituições de Ensino Superior (IES) e, também, nas escolas participantes (OLIVEIRA; BARBOSA, 2013; FERREIRA et al., 2015; PRODÓCIMO et al., 2015; SANTOS et al., 2015; SANTOS et al., 2015). Dados já indicam aumento na procura e diminuição da evasão nos cursos de licenciatura, dentre outros avanços (BORGES, 2010).

Em outros trabalhos publicados, relacionados ao PIBID, verifica-se que os licenciandos vêm conquistando maior espaço de ação na escola, planejando, organizando eventos, projetos e atividades ao lado da comunidade escolar (RABELO, 2016; SOUTO, 2018). Dessa forma rompendo com a lógica disciplinar de formação docente, deixando o modelo de professor aplicacionista tão criticado por Tardif (AMARAL, 2012). Silva (2015), ao analisar os relatórios de atividades dos alunos/ bolsistas, percebeu que além da construção de projetos em equipe, foi notória a participação dos estudantes na gestão da escola, "o que demonstra que vão mais além de interpretar a futura profissão como apenas dar aulas” (SILVA, 2015, p.118).

Para Amaral (2012) o PIBID cria um espaço para a profissionalização docente, tanto para os licenciandos, pela inserção destes na escola, como para os professores da educação básica, pois possibilita que esses se formem também como formadores, sendo considerado pela autora como uma formação em serviço. Além disso, o programa possibilita a interação entre as dimensões acadêmica e profissional da formação docente quando assume e reconhece o professor da escola como parceiro no processo de formação juntamente com os professores das IES (VILELA, 2009). 
Massena e Siqueira (2016) afirmam que ações como o PIBID valorizam a escola pública como espaço de formação, possibilitando que nossos alunos aprendam na prática e com a prática, seja com a vivência do cotidiano escolar, com o planejamento das atividades, com as possibilidades de uso de materiais diferenciados ou abordagens didáticas inovadoras e pelos espaços de reflexão da prática docente que são criados pelo PIBID (PAREDES; GUIMARÃES, 2013; CARVALHO; RAZUCK, 2015).

O PIBID na Universidade de Brasília teve seu início em 2009 com os subprojetos de Química, Física, Biologia e Matemática (CAVALLIN, 2011; CARVALHO; RAZUCK, 2015). O PIBID de Ciências Naturais começou suas atividades no edital CAPES 01/2011, tendo início em julho de 2011.

$\mathrm{Na}$ dinâmica de trabalho do PIBID de Ciências Naturais cada escola sempre trabalhou com um grupo de seis alunos sob a orientação de um professor supervisor (coletivo da escola), sendo que esse juntamente com seus alunos decidia os horários das reuniões e o modo da divisão de trabalho ao longo da semana. Cada aluno deveria cumprir dois turnos de aula com o professor e um turno de coordenação com o grupo na escola por semana. De modo geral, os alunos preferiam trabalhar em duplas, mas, quando necessário, mais alunos poderiam participar de uma mesma atividade. Semanalmente era realizada uma reunião com todos os alunos de todas as escolas na universidade (coletivo PIBID). Esses dois momentos eram cruciais, coordenação do coletivo da escola e reunião do coletivo PIBID, como será descrito abaixo.

Todo começo de semestre ou quando entravam novos bolsistas ID na escola a primeira semana era destinada para que os alunos apenas observassem e acompanhassem o professor supervisor. Após esse momento de observação o coletivo da escola reunia-se e planejava as atividades que seriam desenvolvidas na semana seguinte. Ao final dessa reunião uma proposta de trabalho era acordada entre o grupo. Na reunião do coletivo PIBID cada grupo de alunos apresentava oralmente numa roda de conversa o que ocorreu na sua escola ao longo da semana, como: resultados e alguma atividade desenvolvida, reflexões e as propostas para as aulas posteriores. Os coordenadores ou até mesmo os supervisores apenas mediavam a discussão. Ao final as propostas de atividades para a próxima semana estavam praticamente fechadas, ficando a cargo do coletivo da escola finalizá-las.

\section{METODOLOGIA}

Para esse estudo utilizamos os relatórios anuais que são entregues para a coordenação institucional e encaminhados para a CAPES. Apesar de termos disponíveis os relatórios de 2011 a 2016, tomamos a decisão de nesse estudo utilizarmos apenas os relatórios de 2014 a 2016, pois o formato do relatório a partir de 2014 permite o maior detalhamento das atividades desenvolvidas pelos bolsistas ID.

Como a fonte de nossos dados são os relatórios entregues pelos bolsistas, essa pesquisa se caracteriza como uma pesquisa documental, pois foi baseada na análise de "materiais que não recebem tratamento analítico ou que ainda podem ser reelaborados de acordo com os objetivos da pesquisa" (GIL, 2002, p. 45). 
Essa característica da pesquisa documental de apenas utilizar fontes primárias, sem tratamento analítico, possibilita diferenciá-la da pesquisa bibliográfica, a qual é baseada em materiais que já passaram por tratamento analítico (SÁSILVA et al., 2009; CECHINEL, et al., 2016). Dessa forma entende-se como documentos primários leis, regulamentos, normas, cartas pareceres, relatórios, diários e memorandos (GIL, 2002; LÜDKE; ANDRÉ, 2017), os quais além de trazerem informações contextualizadas, podem fornecer informações sobre o contexto (LÜDKE; ANDRÉ, 2017).

Os relatórios foram feitos pelos bolsistas ID sob a orientação dos supervisores e coordenadores de cada subprojeto. Nesses relatórios estavam presentes diversas informações, como dados sobre as escolas, os bolsistas, publicações dentre outras. Para esse estudo utilizamos apenas os quadros de descrição das atividades, nos quais os bolsistas descrevem as atividades desenvolvidas nas escolas. Nesse quadro estão presentes três campos: Objetivos, Descrição e Resultados alcançados. Nesses campos os alunos eram orientados a descrever os objetivos de cada atividade, conteúdos e estratégias utilizadas, uma descrição da realização e as impressões do grupo sobre a atividade. Para esse artigo não identificaremos as escolas com os nomes reais, mas por números (Escola 1, 2, 3 e etc.).

Conforme dito acima todas as atividades desenvolvidas foram discutidas e planejadas nas reuniões, nas quais era possível checar o cumprimento ou não dos objetivos propostos, ajustes realizados e registros necessários para preparação dos relatórios. Dessa forma, mesmo o relatório sendo preparado somente no final do ano o registro e descrição das atividades era semanal, possibilitando aos coordenadores e supervisores um acompanhamento real de como cada atividade foi realizada.

Para analisarmos os relatórios nos baseamos na metodologia de análise de conteúdo (BARDIN, 2011), a qual é a mais utilizada para pesquisas documentais (GIL, 2002; SÁ-SILVA et al., 2009; BARDIN, 2011; LÜDKE; ANDRÉ, 2017), por permitir "a descrição do conteúdo manifesto e latente das comunicações" (GIL, 2002, p. 89). Na nossa análise realizamos uma primeira leitura e identificamos quais conteúdos haviam sido abordados em cada atividade e organizamos as atividades por grandes temas, como fisiologia humana ao invés de sistema digestório, respiratório e etc. Depois para cada atividade identificamos as estratégias de ensino que foram utilizadas para abordar cada tema. Para esse estudo consideramos como estratégia de ensino a forma que os bolsistas abordaram o conteúdo em sala de aula, a qual pode ser definida muitas vezes pelo recurso didático escolhido, como uma aula com vídeo por exemplo.

Com os dados organizados pelos conteúdos e estratégias fizemos a leitura dos três campos do quadro de atividades procurando identificar, a partir dos relatos dos bolsistas, indícios de mobilização ou desenvolvimento de saberes docentes indicados por Tardif (2014): saberes da formação profissional, saberes das disciplinas, saberes curriculares e saberes da experiência. Dessa forma, nossas categorias de análise são os próprios saberes indicados por Tardif. 


\section{RESULTADOS E DISCUSSÃO}

\section{Sobre os conteúdos abordados}

Ao longo dos três anos do projeto, os bolsistas ID tiveram a oportunidade de trabalhar com todos os anos do ensino fundamental $\left(6^{\circ}\right.$ ao $\left.9^{\circ}\right)$ abordando diversos conteúdos como apresentado no Quadro 1.

Quadro 1. Temas abordados pelos bolsistas ID nas escolas parceiras entre os anos de 2014-2016.

\begin{tabular}{|c|c|}
\hline Ano & \multicolumn{1}{c|}{ Conteúdos } \\
\hline $6^{\circ}$ & Formação da Terra; Rochas, minerais e solo; Uso da água; Fósseis; Ecologia. \\
\hline 70 & Origem da vida e Evolução; Seres vivos. \\
\hline $8^{\circ}$ & $\begin{array}{l}\text { Citologia e Histologia; Nutrição Humana; Fisiologia Humana; Sexualidade; } \\
\text { Genética Básica. }\end{array}$ \\
\hline 90 & $\begin{array}{l}\text { Unidades de Medida; Cinemática; Leis de Newton; Grandezas físicas; } \\
\text { Química no cotidiano; Propriedades dos materiais; Modelos atômicos; Tabela } \\
\text { periódica; Distribuição eletrônica; Ligações químicas; Reações químicas. }\end{array}$ \\
\hline $\begin{array}{c}\text { Temas } \\
\text { Diferenciados }\end{array}$ & $\begin{array}{l}\text { Higiene pessoal; Relações interpessoais; Concepção de Ciência; Educação } \\
\text { para saúde; Alimentação e cultura; Drogas; Estética e padrões de beleza }\end{array}$ \\
\hline
\end{tabular}

Os conteúdos aqui apresentados (Quadro 1) estão organizados em grandes temas, mas nos relatórios os temas de cada atividade estão detalhados, por exemplo, dentro do grande tema Ecologia foram abordados conceitos básicos de ecologia e as relações dos organismos com o ambiente. Esse detalhamento não foi feito aqui por terem sido realizadas mais de 200 aulas organizadas em 174 conteúdos. Vale destacar que apesar de entendermos que as aprendizagens na escola não se limitam apenas aos conteúdos conceituais, mas também aos procedimentos e atitudes (COLL et al., 1998), nesse trabalho nos limitaremos em abordar apenas os conteúdos conceituais trabalhados pelos bolsistas.

Ao analisarmos os temas abordados podemos perceber que em sua maioria são temas tradicionalmente tratados no ensino fundamental e que são indicados para esse segmento nos Parâmetros Curriculares Nacionais (BRASIL, 1997) e no currículo da Secretaria de Educação do Distrito Federal (GDF, 2016). Os conhecimentos sobre os conteúdos abordados em sala de aula estão relacionados às disciplinas que os bolsistas cursam ao longo do curso (química e física, p. ex.) e são de fundamental importância para que eles possam atuar como professores. Para Tardif (2014) esse conjunto de conhecimentos se constitui um saber docente, o saber disciplinar, o qual se inicia nas disciplinas, mas deve ser validado pela prática. Não adianta somente repetir o que se aprendeu na disciplina da universidade, é necessário adequá-lo ao seu público. Nesse momento de escolhas outro saber é mobilizado, o saber curricular pois é necessário conhecer o que se 
pede nos currículos para se fazer as escolhas, bem como as possíveis formas de abordagem mais indicadas para cada ano e faixa etária. A medida que os bolsistas vivenciam essas tomadas de decisão e implementam suas propostas outro saber é desenvolvido, o saber experiencial, o qual mobiliza outros saberes, validandoos e possibilitando o desenvolvimento de repertórios para outras oportunidades. Para Carmo e Rocha (2016) quando o licenciando promove modificações ou adequações nos conteúdos para trabalhar em sala de aula ele está realizando uma atividade que é exclusiva da docência, que requer não somente o conhecimento de conteúdos, mas também habilidades pedagógicas.

Ao analisarmos os conteúdos abordados notamos a presença de assuntos ou temas que não são tradicionais nos anos finais, como higiene pessoal, relações interpessoais, concepção de ciência, alimentação e cultura e estética e padrões de beleza, agrupados como “Temas Diferenciados" (Quadro 1), foram temas abordados em anos distintos em mais de uma situação. Como a abordagem desses temas foi feita de forma diferenciada, iremos descrever apenas algumas situações abaixo.

A temática higiene pessoal foi abordada em escolas diferentes e com motivações diferentes. Em duas escolas o tópico foi tratado com o objetivo de promoção de saúde e hábitos alimentares. Mas em uma das escolas, em dois momentos, a demanda veio dos bolsistas ID e dos próprios alunos que reclamavam da falta de higiene de alguns colegas, como podemos observar pelos objetivos propostos nos dois momentos:

"Conscientizar sobre a importância da bigiene pessoal, melhorar a autoestima e o autocuidado, tanto em aspectos físicos quanto mentais.” (Escola 5 - 2015)

"Despertar o interesse para a Higiene e o Cuidado Pessoal. Reconhecer a importância de apresentar uma higiene adequada." (Escola 5 - 2016)

Propor intervenções diante de situações que surgem no dia a dia da escola requer do professor e bolsistas um olhar atento para suas turmas e planejamento para que as ações surtam o efeito desejado, como podemos constatar pelos relatos abaixo:

"Com as apresentações podemos perceber que de fato os alunos entenderam, por que é importante a higiene pessoal. [...] O fato dos alunos terem participado ativamente foi um ponto determinante para o sucesso da atividade." (Escola 5 - 2015)

"Através das falas dos discentes pode-se perceber que de fato eles entenderam porque é importante ter uma higiene pessoal adequada, mas em suas atitudes os educandos não demonstram o mesmo entendimento em alguns momentos.” (Escola 5 - 2016)

O tema relações interpessoais foi abordado em duas escolas diferentes. Em uma das escolas os bolsistas ID promoveram uma roda de conversa com os alunos para discutir a importância do estudo, educação e as relações entre eles. Ao final os bolsistas ID ficaram satisfeitos com o resultado da atividade como é indicado na transcrição abaixo: 
"Foi uma das aulas mais produtivas do bimestre, pois mostrar para o aluno que ele deve estar aberto a receber críticas e a fazer críticas, possibilitando uma desconstrução de que o aluno é aquele que escuta e o professor é a quele que fala. Foi discutido que o processo de educaşão acontece nas relações e ter autonomia e senso crítico em determinados momentos é essencial. Durante a roda de conversa foi discutido assuntos sobre comportamento, participação, apresentação do projeto, dentre outras, Por fim, a aula foi finalizada com uma simples revisão de tudo que foi passado nas semanas anteriores." (Escola 1 - 2015)

Ainda com o tema de relações interpessoais, porém em outra escola, um outro grupo de bolsistas realizou uma atividade lúdica que valorizava as relações de respeito e confiança no trabalho em grupo. Ao descrever o resultado da atividade o grupo relatou:

"[... A confiança que um teve no outro foi fundamental para que eles pudessem permanecer naquela posição e a autoconfiança também, pois se um desistisse todos iam cair. Com a atividade os alunos também puderam compreender a importancia do trabalho em equipe." (Escola 5 - 2016)

A partir desses relatos podemos perceber que os bolsistas e professores supervisores estão preocupados não somente com a aprendizagem de conceitos, mas também com a aprendizagem de atitudes e valores importantes para o desenvolvimento dos alunos.

Essa ressignificação do conceito de conteúdo está presente nos Parâmetros Curriculares Nacionais (PCN):

"O projeto educacional expresso nos Parâmetros Curriculares Nacionais demanda uma reflexão sobre a seleção de conteúdos, como também exige uma ressignificação, em que a noção de conteúdo escolar se amplia para além de fatos e conceitos, passando a incluir procedimentos, valores, normas e atitudes." (BRASIL, 1997, p. 51).

Outro tema pouco frequente em sala de aula é a concepção de ciência e a importância de estudar ciências. Os bolsistas ID de uma escola propuseram um debate com os alunos com os seguintes objetivos:

"Dialogar acerca da concepção de Ciência, visão de Cientista e sobre a importância de estudar ciências.” (Escola 5 - 2015)

Ao final da atividade os bolsistas relatam os seguintes resultados:

"Com a tarefa proposta, percebeu-se que os aprendizes possuiam uma visão deformada e reducionista de Ciência e Cientista. Em alguns casos, os estudantes consideravam como Ciência apenas a área referente à matéria escolar de Ciências Naturais. Para os mesmos, o cientista é um homem que fica isolado da realidade, um gênio de óculos que fica trancado no laboratório de química manipulando vidrarias com experimentos.” (Escola 5 - 2015) 
"Com a discussão, verificou-se que os discentes construiram novas concepcões referentes ao conceito de Cientista, pois os mesmos compreenderam que fažer ciência não está restrito a figura masculina e a minoria." (Escola 5 - 2015)

Abordar a concepção de ciência e ajudar os alunos a compreenderem como é o trabalho do cientista contribui para que os alunos possam construir uma boa relação com os conteúdos de ciências que virão pela frente, pois à medida que progridem nos anos escolares a quantidade e complexidade desses conteúdos aumenta.

A temática sobre estética e beleza no ensino fundamental é um desafio necessário para os professores, pois os alunos desse segmento precisam conhecer seu corpo, entendê-lo e aceitá-lo. Um dos grupos de bolsistas juntamente com seu professor aceitou esse desafio e propôs uma atividade com os seguintes objetivos:

"Compreender o desenvolvimento dos padrões de beleza a ao longo do tempo; Entender como a sociedade moldou isso; Ter entendimento de que a mídia influência nos moldes sociais." (Escola 5 - 2016)

O resultado dessa atividade foi bem satisfatório para o os bolsistas:

"A atividade possibilitou a reflexão acerca dos padrões de beleza emanados pelos meios midiáticos, uma vez que os discentes perceberam, por meio das imagens contidas nos slides, que em diferentes tempos históricos, os padrões mudavam. O fator mais interessante dessa atividade ocorreu quando os educandos não escolheram imagens de pessoas que estavam dentro dos padrões de beleza atual, isso mostrou como os mesmos já concebem a existência de um único padrão de beleza." (Escola 5 - 2016)

A continuidade dessa temática possibilitou abordar outros temas relacionados como podemos observar pelas proposições indicadas:

"Compreender de como os distúrbios alimentares e corporais, estão ligados com os padrões estabelecidos pela sociedade; Refletir sobre nossa concepscão de corpo perfeito e construção de uma necessidade de respeito as diferenças.” (Escola 5 - 2016)

Os resultados descritos pelos bolsistas indicam o sucesso dessa abordagem:

"Os alunos participaram bastante, principalmente os meninos. Isso foi algo que incomodou, porque elas são as que mais sofrem com os padrões de beleza, muitos compreenderam que a mídia influencia muito nos padrões e que isso deve ser quebrado, pois entendem que diferenças existem e devem ser respeitadas." (Escola 5 - 2016)

Abordar temas que não são tradicionais na escola ou abordar de forma diferenciada alguns temas comuns ao ensino indicam capacidade de observação dos bolsistas ID, sensibilidade às questões emergentes na sala de aula e uma reflexão crítica sobre a prática docente. O desenvolvimento e mobilização 
desses saberes durante a ação na prática docente são muito importantes para os futuros professores, pois de modo geral os saberes oriundos das disciplinas são desvinculados da atuação profissional (PIMENTA; LIMA, 2006).

Ao aprender a reconhecer necessidades nas turmas e planejar atividades baseado nelas, possibilita aos bolsistas ID desenvolverem o saber experiencial, que vem pela experiência, mas não uma experiência só vivenciada, mas sim reflexiva. Para Tardif (2014) esse contato com a realidade escolar possibilita que o professor desenvolva o seu habitus, um "saber-ser e saber-fazer individual e profissional validado pelo trabalho cotidiano" (TARDIF, 2014, p.49)

\section{Sobre as estratégias de ensino}

Para abordar os conteúdos indicados no Quadro 1 os bolsistas ID utilizaram diversas estratégias de ensino, num total de 281. Essas estratégias foram agrupadas em 13 categorias, as quais são descritas no Quadro 2.

A aula expositiva foi a estratégia mais utilizada pelos bolsistas, cerca $39,5 \%$ das vezes. Outras duas estratégias muito utilizadas foram as aulas com experimentação e com atividades lúdicas (cerca de $12 \%$ para cada uma delas). As demais estratégias foram utilizadas em menos de 10\% das atividades (Quadro 2). Guimarães et al. (2006) encontraram resultados semelhantes ao estudarem os modelos didáticos utilizados por professores de ciências, com cerca de $30 \%$ das aulas sendo expositivas. Porém, nessa pesquisa as aulas práticas e experimentais são mais frequentes o que pode ser explicado pela dificuldade em diferenciar aulas prática de experimentais.

Ao lermos os relatos dos alunos percebemos que as aulas expositivas não foram apenas uma mera exposição dos conteúdos, mas sim uma aula dialogada, muitas vezes mediada com imagens e complementada com outras estratégias, como podemos notar pelas transcrições abaixo:

"A atividade foi desenvolvida através do dialogismo e debate entre os estudantes e os pibidianos,
expondo oralmente quais foram os fenômenos essenciais para a condição atual do universo. Para a
construção e aprofundamento desse diálogo o uso da lousa foi essencial, escrevermos de acordo com a
ordem cronológica e evolutiva relatada pelos estudantes [...]" (Escola 3 - 2016)

"Deu-se uma aula com slides ilustrativos para mostrar o funcionamento do sistema respiratório através de exposição, em um primeiro momento. [...] Em seguida foi mostrado uma representação com garrafa pet que imita o que acontece com nosso corpo quando respiramos, para que possa visualizado de forma mais compreensivel todo o processo, a fim de se tenha melhor entendimento." (Escola 1 - 2014)

Novamente vale ressaltar que a aula expositiva foi mais comum quando eles utilizaram apenas uma estratégia, aproximadamente $54 \%$ das vezes, nas demais oportunidades ela foi utilizada em conjunto com outras (Quadro 2). 
As contribuições do PIBID para o desenvolvimento dos saberes docentes:

A experiência da Licenciatura em Ciências Naturais, Universidade de Brasília

Quadro 2. Estratégias utilizadas em sala de aula pelos bolsistas ID entre 2014-2016.

\begin{tabular}{|c|c|c|}
\hline Estratégia & Descrição & $\%$ \\
\hline Aula expositiva & $\begin{array}{l}\text { Aulas e atividades que os bolsistas fizeram a exposição dos } \\
\text { conteúdos exclusivamente de forma oral com o auxílio do quadro } \\
\text { branco ou com o uso de imagens com datashow. }\end{array}$ & 39,5 \\
\hline Aula com vídeo & Aulas que o vídeo foi utilizado como recurso didático. & 5,0 \\
\hline $\begin{array}{l}\text { Modelos e } \\
\text { modelagens }\end{array}$ & $\begin{array}{l}\text { As atividades em que os alunos manipulam e observam modelos } \\
\text { prontos, constroem modelos ou até mesmo realizam simulações. }\end{array}$ & 6,0 \\
\hline Observação & Aulas que os alunos observaram amostras ou espécimes. & 5,0 \\
\hline Experimentação & $\begin{array}{l}\text { Aula onde os alunos realizam ou observam atividades } \\
\text { experimentais, nas quais são manipulados materiais e realizados } \\
\text { procedimentos característicos de experimentos laboratoriais, } \\
\text { além de aulas de campo e outras atividades práticas. }\end{array}$ & 11,7 \\
\hline Mapa conceitual & $\begin{array}{l}\text { Aulas com mapas conceituais são aquelas em que os alunos } \\
\text { sintetizam e esquematizam os conteúdos abordados e } \\
\text { estabelecem relações entre esses conteúdos. }\end{array}$ & 1,8 \\
\hline $\begin{array}{l}\text { Atividades } \\
\text { avaliativas }\end{array}$ & Atividades de avaliação elaboradas e aplicadas pelos bolsistas. & 1,8 \\
\hline Discussões & $\begin{array}{l}\text { Discussões e debates orientados, onde eram propostos temas } \\
\text { para a discussão e fornecidos materiais para subsidiá-las. } \\
\text { Essas discussões variaram desde debates entre grupos, rodas } \\
\text { de conversa e seminários. }\end{array}$ & 4,3 \\
\hline Leitura & $\begin{array}{l}\text { Leitura realizada em sala de aula baseada em textos presentes nos } \\
\text { livros didáticos ou textos complementares trazidos pelos bolsistas. }\end{array}$ & 5,0 \\
\hline Aula lúdica & $\begin{array}{l}\text { Atividades que o lúdico foi o objetivo principal, como: jogos, } \\
\text { dinâmicas, teatro e paródias. }\end{array}$ & 12,1 \\
\hline Exercícios & $\begin{array}{l}\text { Aulas que tiveram como objetivo a resolução de exercícios ou } \\
\text { problemas retirados do livro didático ou de listas elaboradas } \\
\text { pelos bolsistas. }\end{array}$ & 6,4 \\
\hline Pesquisa & $\begin{array}{l}\text { Atividades que os alunos foram orientados a pesquisarem sobre } \\
\text { determinado tema e apresentassem os resultados para a turma. }\end{array}$ & 1,4 \\
\hline
\end{tabular}


Ainda sobre a utilização de estratégias, um outro dado que chamou a atenção foi a utilização de mais de uma para abordar os conteúdos. Baseado nos relatos, verificou-se que ao abordarem os conteúdos, em apenas 35,2\% das vezes os bolsistas utilizaram uma única estratégia em sala de aula, utilizando pelo menos duas em cerca de $18 \%$ das aulas e mais de duas nas demais aulas.

As estratégias de ensino geralmente são aprendidas em disciplinas como didática ou metodologia de ensino, sendo relacionadas a teorias de aprendizagem e outros aspectos do desenvolvimento cognitivo. Dessa forma, quando os bolsistas escolhem determinada estratégia para abordar um determinado conteúdo estão mobilizando diversos saberes como da profissão docente, disciplinares e curriculares, sendo que quando essa escolha vem de experiências anteriores com as turmas ou com os conteúdos o saber experiencial também está presente (TARDIF, 2014). A escolha de mais de uma estratégia para abordar um conteúdo pode indicar não somente a mobilização de saberes adquiridos anteriormente (como disciplinares e curriculares, p. ex.), mas também o desenvolvimento de saberes oriundos da prática, devido às experiências anteriores com os alunos (saber da experiência).

Os bolsistas proporcionaram aos alunos oportunidades de terem contato com amostras e espécimes, bem como com atividades laboratoriais como podemos constatar pelas descrições abaixo:

"Para a realização dessa atividade os estudantes tiveram acesso a artrópodes que estão conservados em um vidro transparente para que eles observassem aquele animal ali dentro.” (Escola 1- 2015)

"De inicio a turma de alunos foi dividida em quatro grupos, a cada grupo foi entregue um roteiro de uma experimentação distinta, bem como os materiais a serem utilizados em tal experimentação. Em seguida, um grupo de cada ver, foi explicando e realizando, para o restante da turma, os procedimentos contidos em seu roteiro, com posterior análise dos resultados de cada experimento. [...] Experimentações realizadas: $A$ ação da saliva; Importância da mastigação; $O$ movimento da digestão; O detergente da digestão.” (Escola 1 - 2014)

Os bolsistas ID tiveram oportunidade de realizarem algumas atividades de avaliação com os alunos, seguindo as orientações dos professores supervisores, como podemos constatar pelo relato:

"A prova foi elaborada por alunos no PIBID, onde a mesma era constituida por questões descritivas e dissertativas, com peso total de 4 pontos.” (Escola 1 - 2015)

Permitir que os bolsistas elaborem, apliquem e corrijam avaliações, sob a supervisão do professor, é uma ótima oportunidade de mobilização de saberes, pois requer conhecimento dos conteúdos, concepções de ensino-aprendizagem, estratégias de avaliação e conhecimento sobre as turmas.

Em algumas situações os alunos realizaram discussões e debates orientados, onde eram propostos temas para a discussão e fornecidos materiais para subsidiá-las. Essas discussões variaram desde debates entre grupos, rodas de conversa e seminários. 
As contribuições do PIBID para o desenvolvimento dos saberes docentes:

A experiência da Licenciatura em Ciências Naturais, Universidade de Brasília

"Os alunos fizeram uma grande roda e dentro foi espalhado uma lista de palavras em folhas diferentes que se agrupam no tema drogas, desde o contexto cientifico ao do cotidiano. Cada aluno pegou aproximadamente 4 palavras diferentes e teve que falar o que se sabe daquela palavra e anotar. Foi construido um agrupamento de conceitos que se interligam e que tem como partida as drogas no contexto social." (Escola 5 - 2016)

"O nivel das apresentações foi diferenciado, alguns grupos dominaram completamente o conteúdo, conseguindo sanar as dividas que surgiram, entretanto, outros grupos somente leram os slides, não conseguiram dominar o conteúdo e ficaram inseguros por isto. Dois grupos realizaram uma roda de conversa utilizando o livro didático como suporte. Os alunos que utilizaram a peça teatral surpreenderam a turma, pois os mesmos conseguiram abordar o tema de forma simples e rica em informações, estes alunos fižeram um "rap" para finalizar a apresentação." (Escola 1 - 2015)

Nas atividades de leitura os bolsistas utilizaram textos presentes nos livros didáticos ou textos complementares trazidos por eles:

"A mediação dos conteúdos se inicion com um texto, no caso dos protistas foi utilizado um texto que evidenciava a grande quantidade de foraminiferos, protozoários, parentes próximos das amebas, que são encontrados na areia da praia. Para os fungos, foi utilizado o texto: "O maior ser vivo do mundo". Foram realizadas leituras coletivas dos textos e em seguida era iniciada uma roda de debates, para verificar conhecimentos prévios e esclarecer dúvidas [...]”" (Escola 3 - 2016)

Ao trazer materiais complementares para as atividades, indica não só a preocupação com o aprendizado dos alunos, mas também um conhecimento do que é necessário para complementar o que já foi trabalhado em sala de aula, indicando um domínio sobre o conteúdo, um saber disciplinar (TARDIF, 2014).

Caracterizar as atividades lúdicas não foi uma tarefa fácil, pois a maioria das atividades que os bolsistas ID desenvolveram na escola envolvia alguma ludicidade. Percebemos pelos relatos que não só a ludicidade foi o objetivo das atividades propostas:

"Atividade lúdica denominada "caça ao tesouro", composta por cinco envelopes de diferentes cores, com cinco envelopes menores dentro. Cada envelope menor contém uma pergunta, que quando respondida corretamente dá acesso ao conteúdo deste envelope. Dentro de cada envelope se tem uma imagem relacionada a alguma doença causada por um ser deste reino. Ao acertar a pergunta o envelope é aberto e a imagem mostrado aos alunos do grupo, esta imagem é sobre o transmissor da doença, sintomas ou fatores favoráveis para a ocorrência da patologia." (Escola 1 - 2015)

Foram propostas algumas pesquisas pelos bolsistas, sempre em grupo e de forma contextualizada. Propor atividades como essas sempre são um desafio na escola, principalmente quando necessitam de autonomia por parte dos alunos, mas quando bem orientadas podemos obter bons resultados:

"Após as aulas teóricas referentes aos biomas nacionais e mundiais, o enfoque foi para o Cerrado, por ser o Bioma predominante em nossa localização. Então foi organizado um trabalho em grupo, onde cada turma foi dividida em 3 grandes grupos. Cada grupo ficou com um tema: frutas, plantas 
e animais do Cerrado, para que pudessem produ₹ir materiais para apresentar para toda a turma, juntamente com nosso auxilio. Posteriormente, foram selecionados os melhores trabalhos em relação às turmas, para que fossem apresentados para toda a escola." (Escola 3 - 2015)

Ao escolher determinadas estratégias para abordar os conteúdos os alunos tendem a reelaborar conhecimentos que adquiriram de sua formação e adequações pedagógicas, promovendo o desenvolvimento de novos saberes (TARDIF, 2014). Além disso, uso de diferentes estratégias de ensino também pode ser considerado como um saber da formação profissional, uma vez que disciplinas de metodologia de ensino e estágios supervisionados enfatizam a importância das estratégias para atender a diversidade da sala de aula.

\section{Sobre os resultados das atividades}

Nos resultados das atividades descritos nos relatórios aparecem com frequência a preocupação com a aprendizagem e formação integral do estudante. Dessa forma, os futuros professores estão mobilizando saberes da formação profissional vistos no curso de licenciatura em disciplinas da pedagogia e psicologia, como no trecho abaixo:

"Sabemos que não é a forma correta e que não soubemos caminhar com o conteúdo programático durante o primeiro semestre de forma a terminá-lo, mas foi a forma que encontramos para não deixar os alunos prejudicados." (Escola 4 - 2014)

Para Tardif (2014, p. 50), “os saberes experienciais fornecem aos professores as certezas relativas a seu contexto de trabalho na escola e possuem três objetos que constituem a própria prática docente e que só se revela através dela". O primeiro objeto está relacionado às relações e interações que os professores estabelecem e desenvolvem com os demais atores no campo de sua prática.

"Os exercícios que os alunos não conseguiam fazer sozinhos a gente resolvia juntos e eles sempre conseguiam chegar ao resultado final sem grandes dificuldades.” (Escola 2 - 2014)

O diálogo envolve aspectos sociais, o professor procura compreender o aluno. Parar e ouvir permite ao professor avaliar sua aula e caso necessário tomar novos rumos. Esse ato trata-se tanto de um saber experiencial quanto de saberes da formação profissional.

O segundo objeto para Tardif (2014) está relacionado as diversas obrigações e normas às quais seu trabalho deve submeter-se.

"Os alunos prestaram muito atenção por terem que copiar o que ditávamos e quando tínhamos que explicar eles também prestavam a atenção, alguns alunos atrapalhavam durante o ditado, mas conseguimos controlar a situação.” (Escola 2 - 2014)

O terceiro e último, entende a instituição enquanto meio organizado e composto por funções diversificadas (TARDIF, 2014). Ao abordarem o tema 
sexualidade, os licenciandos entenderam a função formadora da escola e buscaram um profissional externo habilitado para dividirem essa função:

"Foi pedido aos alunos que escrevessem suas dúvidas sobre sexualidade, gravidez, sem se identificarem, essas perguntas foram entregues a uma professora psicóloga convidada a ministrar uma palestra para os alunos, a partir das dívidas entregues anteriormente." (Escola 1 - 2014)

Uma vez que os saberes experienciais são adquiridos a partir da prática cotidiana da profissão, eles não favorecem apenas certezas "experienciais", mas permite também uma avaliação de outros saberes (TARDIF, 2014, p.53).

"As turmas mais agitadas se comportaram no momento do jogo, foi bastante gratificante. Acredita-se que os mesmos puderam sanar suas dúvidas sobre o tema." (Escola 1 - 2014)

É possível verificar a análise do uso de estratégias de ensino diferenciadas, onde o licenciando avalia um saber da formação profissional:

"Porém deve ser ressaltado que tal conteúdo é reconhecido por uma certa dificuldade devido à grande quantidade nomes de ossos e articulações faz̧endo com que os alunos já criassem certo receio. No entanto tal medo foi sendo quebrado ao praticarmos exercícios, cujo o objetivo maior foi de tirar a maior quantidade de dívidas possiveis.” (Escola 2 - 2014)

A prática pode ser vista como um processo de aprendizagem provocando um efeito de retomada crítica dos saberes adquiridos antes ou fora da prática profissional. (TARDIF, 2014, p.53). A presença nos relatórios dos termos "como já esperado" e "nota-se mais uma vez", demonstra uma reflexão sobre sua própria prática, talvez porque já traziam esses saberes. Entretanto, em alguns momentos foram surpreendidos, mostrando a relevância dos saberes experienciais, uma vez que outros saberes (disciplinares, curriculares e da formação profissional) não foram suficientes para aquele momento, encontrando o limite desses saberes (TARDIF, 2014):

"Como já esperado, a aula foi bastante movimentada devido o tema ser de muito conbecimento prévio entre os alunos. Além disso, de certa forma, a turma nos surpreendeu com perguntas muito interessante e maduras para a idade deles, variando de perguntas desde a anatomia interna até os métodos de prevenção utilizados durante, antes e após o ato sexual." (Escola 2 - 2014)

"Nota-se mais uma vez, que o diferente atrai os alunos." (Escola 4 - 2014)

Algumas questões discutidas não são aprendidas na universidade e nem tão pouco consta no currículo da escola, mas mobilizam conhecimentos de vida durante as discussões:

"Assuntos sobre gravide₹ foram bastante debatidos, entretanto grande parte da turma saiu da aula convicto que para tudo existe um tempo e que na maioria das vezes não é bom antecipar alguns fatos. Ficando orientados que caso ocorra, usem preservativos." (Escola 2 - 2014) 
"[...] Tais perguntas foram respondidas a sério dentro do âmbito cientifico, é claro, entretanto sendo complementadas com respostas pessoais, tentando fazer com que os alunos possam ter um âmbito de visão maior e que eles possam elaborar uma visão crítica sobre o determinado assunto." (Escola 2 - 2014)

O saber da experiência vem da prática, das situações, das incertezas e das decisões na ação. O professor é um profissional que também adquire e desenvolve seus conhecimentos a partir da prática e de sua vivência com as condições de trabalho (NUNES, 2001), por isso Nóvoa (2009) defende que a profissão docente deve ser construída dentro da profissão.

Os saberes docentes vão progressivamente sendo aprimorados ao longo do tempo, consolidados na ação e no trabalho no ambiente escolar, sendo impossível estudá-los ou desenvolvê-los fora desse ambiente (TARDIF, 2000). Estudar casos concretos e refletir sobre as ações do professor na escola permite criarmos o hábito de reflexão nos futuros professores (NÓVOA, 2009).

A experiência compartilhada e orientada proporcionada pelo PIBID aos seus participantes, qualifica e valida o processo de formação destes. Fazendo com que as ações dos bolsistas ganhem contextos e referências de diversas naturezas, como acadêmicas, profissionais e pessoais, enriquecendo o repertório de estratégias e ações para futuras intervenções dos bolsistas.

\section{CONSIDERACְ̃̃ES FINAIS}

Os relatos apresentados acima indicam que os bolsistas ID participantes do subprojeto Ciências Naturais mobilizaram e desenvolveram saberes relacionados à profissão docente, indicando que essa proposta tende a romper com um modelo de formação aplicacionista do conhecimento, respeitando e reconhecendo a escola e seus professores como colaboradores e parceiros no processo de formação, possibilitando a integração entre os saberes.

$\mathrm{O}$ PIBID ao possibilitar que os alunos entrem na escola precocemente, de forma coletiva e colaborativa, garante que esse primeiro contato não será solitário e desorientado. Permite que a escola e seus professores "apresentem" a realidade docente para os bolsistas, confrontando saberes já adquiridos e essa realidade. Nesse formato possibilita que os alunos aprendam a viver na escola, com suas regras, valores e rotinas, contribuindo para que saberes sejam consolidados, reestruturados e novos sejam gerados.

Apesar das contribuições do PIBID na formação docente apresentadas acima, o programa ainda possui limitações quanto a sua abrangência, pois restrições orçamentárias limitam o número de alunos e supervisores que podem participar do programa, bem como a integração do programa com as demais ações de formação de professores nas IES. Institucionalizar o PIBID nos programas de licenciaturas seria uma forma de promover um maior diálogo entre os saberes docentes ao longo do curso. 


\section{AGRADECIMENTOS}

Agradecemos às escolas e seus profissionais que participaram do PIBID de Ciências Naturais e em especial aos professores supervisores que receberam, acolheram e orientaram os bolsistas ID de Ciências Naturais.

\section{REFERÊNCIAS BIBLIOGRÁFICAS}

AMARAL, E. M. R. Avaliando contribuições para a formação docente: uma análise de atividades realizadas no PIBID-Química da UFRPE. Química Nova na Escola, 34(4): 229-239, 2012.

AYRES, A. C. M.; SELLES, S. E. História da formação de professores: diálogos com a disciplina escolar ciências no ensino fundamental. Ensaio, 14(2): 95-107, 2012.

BARDIN, L. Análise de conteúdo. São Paulo: Edições 70, 2011.

BORGES, M. C. A formação de professores na UFMT: o PIBID como experiência desafiadora. Rev. Triâng. Ens. Pesq. Ext., 3(2): 163-176, 2010.

BRASIL. MINISTÉRIO DA EDUCAÇÃO. Parâmetros Curriculares Nacionais: Introdução aos Parâmetros Curriculares Nacionais. Brasília: MEC, 1997.

CAMPOS, L. M. L.; DINIZ, R. E. S. A prática como fonte de aprendizagem e o saber da experiência: o que dizem professores de ciências e de biologia. Investigações em Ensino de Ciências, 6(1): 79-96, 2001.

CAPES - MINISTÉRIO DA EDUCAÇÃO. Relatórios e dados. Disponível em: http://www. capes.gov.br/educacao-basica/capespibid/relatorios-e-dados, 2018. Acesso em : 25 mar. 2018).

CARMO, E. M.; ROCHA, W. K. S. A produção dos saberes docentes e o estágio supervisionado: o que dizem as narrativas dos alunos. Inter-ação, 41(3): 725-742, 2016.

CARVALHO, A. P.; RAZUCK, R. C. S. R. O programa Institucional de Bolsa de Iniciação à Docência sob a ótica dos professores supervisores de química: contribuições ao processo de formação docente. Revista Ibero-Americana de Educação, 68(1): 9-28, 2015.

CAVALLIN, E. C. Implantação e trajetória do PIBID/Química/UnB no período de 20092011: Análise e relato no olhar do licenciando. Trabalho de conclusão de curso (Licenciatura em Química) - Instituto de Química, Universidade de Brasília, Brasília, 2011.

CECHINEL, A.; FONTANA, S. A. P.; GIUSTINA, K. P. D.; PEREIRA, A. S.; PRADO, S. S. Estudo/Análise documental: uma revisão teórica e metodológica. Criar Educação, 5(1): 1-7, 2016.

CHAVES, T. V.; TERRAZAN, E. A. Um estudo sobre as formas de organização da formação pedagógica em cursos de licenciatura. Formação Docente, 7(13): 31-44, 2015.

COLL, C.; POZO J. I.; SARABIA B.; VALLS, E. Os conteúdos na reforma: ensino e aprendizagem de conceitos, procedimentos e atitudes. Porto Alegre: Artmed; 2000. 
CUNHA, E. R. Os saberes docentes ou saberes dos professores. Revista Cocar, 1(2): 31-39, 2007.

DIAS-DA-SILVA, M. H. G. Política de formação de professores no Brasil: as ciladas da restruturação das licenciaturas. Perspectiva, 23(2): 381-406, 2005.

FERREIRA, F. S.; VASCONCELOS, C. R. A.; COLARES, M. L. I. S. Política de formação docente: da implementação do PIBID como incentivo à prática docente à aproximação universidade e escola. Revista e Emancipação, 8(2): 11-35, 2015.

GATTI, B. A. Formação de Professores no Brasil: características e problemas. Revista Educ. Soc., 31(113): 1355-1379, 2010.

GATTI, B. A.; BARRETO, E. S. S. Professores do Brasil: impasses e desafios. Brasília, DF: UNESCO, 2009.

GATTI, B. A.; BARRETO, E. S. S.; ANDRE, M. E. D. A. Políticas docentes no Brasil: um estado da arte. Brasília, DF: UNESCO, 2011.

Gauthier, C; MARTINeAU, S.; Desbiens, J. F. Por uma teoria da Pedagogia: pesquisas contemporâneas sobre o saber docente. Ijuí: UniJuí, 1998.

GDF, Secretaria de Educação do Distrito Federal. Currículo em movimento da Educação Básica: Ensino Fundamental Anos Finais. Disponível em: http://www.se.df.gov.br/component/ content/article/282-midias/443-curriculoemmovimento.html, 2016. Acesso em: 22 jul. 2017).

GIL, A. C. Como elaborar projetos de pesquisa. $4^{a}$ ed., São Paulo: ATLAS, 2002.

GUIMARÃES, G. M. A.; ECHEVERRIA, A. R.; MORAES, I. J. Modelos didáticos no discurso dos professores de Ciências. Investigações em Ensino de Ciências, 11(3): 303-322, 2006.

LÜDKE, M. ANDRÉ, M. E. D. A. Pesquisa em Educação: abordagens qualitativas. $2^{\mathrm{a}}$ ed., Rio de Janeiro: EPU, 2017.

MASSENA, E. P.; MONTEIRO, A. M. F. C. Marcas do currículo na formação do licenciando: uma análise a partir dos temas de trabalhos finais de curso de licenciatura em química da UFRJ (19982008). Química Nova na Escola, 33: 10-18, 2011.

MASSENA, E. P.; SIQUEIRA, M. Contribuições do PIBID à formação inicial de professores de ciências na perspectiva dos licenciandos. RBPEC, 16(1): 17-34, 2016.

NÓVOA, A. Professores: imagens do futuro presente. Lisboa, Educa, 95p., 2009.

NUNES, C. M. F. Saberes docentes e formação de professores: um breve panorama da pesquisa brasileira. Educação e Sociedade, 74: 27-42, 2001.

OLIVEIRA, A.; BARBOSA, V. S. L. Formação de professores em ciências sociais: desafios e possibilidades a partir do estágio e do PIBID. Revista Eletrônica Inter-Legere, 13: 140-162, 2013.

PAREDES, G. G. O.; GUIMARÃES, O. M. Compreensões e significados sobre o PIBID para a melhoria da formação de professores de biologia, física e química. Química Nova na Escola, 34(4): 266-277, 2013.

PIMENTA, S. G. Formação de professores - saberes da docência e identidade do professor. R. Fac. Educ., 22(2): 72-89, 1996. 
PIMENTA, S. G. Saberes pedagógicos e atividade docente. São Paulo: Cortez, 1999.

PIMENTA, S. G.; LIMA, M. S. L. Estágio e docência: diferentes concepções. Revista Poíesis, 3 (3-4): 5-24, 2006.

PORLÁN, R.; RIVIERO, A.; MARTIN DEL POZO, R. Conocimiento profesional y epistemolía de los profesores I: teoria, métodos e instrumentos. Enseñanza de las Ciencias, 5(2): 155-171, 1997.

PRODÓCIMO, E.; PRADO, G. V. T.; AYOUB, E. PIBID: análise de produções publicadas em periódicos da área da educação. Atos de Pesquisa em Educação, 10(2): 393-410, 2015.

PUENTES, R. V.; AQUINO, O. F.; NETO, A. Q. Profissionalização dos professores: conhecimento, saberes e competências necessárias à docência. Educar, 34:169-184, 2009.

RABELO, L. O. Contribuições e limites do PIBID para permanência de alunos na licenciatura e como suporte para o início da docência. Dissertação de mestrado. USP, 2016.

SÁ-SILVA, J. R.; ALMEIDA, C. D.; GUINDANI, J. F. Pesquisa documental: pistas teóricas e metodológica. Revista Brasileira de História e Ciências Sociais, 1(1): 1-15, 2009.

SANTOS, L. M. C.; ALMEIDA, W. S.; TEIXEIRA, G. B.; MACEDO, J. F.; LIMA, L. S.; SANTOS, E. J. S.; NUNES, M. M.; CARDOSO, S. C.; REIS, Y. F. S.; SUSSUCHI, E. M. A influência do PIBID no processo de formação inicial dos licenciandos em química da UFS/São Cristóvão. Scientia Plena, 11(6):1-8, 2015.

SANTOS, M. Z. M.; SOARES, B. M.; SCHEID, N. M. J. (2015). O PIBID e a formação de professores de ciências biológicas da URI, Santo Ângelo, Brasil. Interacções, 39: 155-174.

SANTOS, W. L. P; SCHNETZLER, R. P. Educação em Química: compromisso com a cidadania. Ijuí: Unijuí, 144p, 2003.

SARMENTO, M. J. A vez e a voz dos professores: contributo para o estudo da cultura organizacional da escola primária. Porto: Ed. Porto, 1994.

SCHEIBE, L. Valorização e formação dos professores para a educação básica: questões desafiadoras para um novo plano nacional de educação. Educ. Soc., 31(112): 981-1000, 2010.

SHULMAN, L. S. Those who understand: knowledge growth in teaching. Educational Researcher, 15(2): 4-14, 1986.

SILVA, G.G. Significações do Pibid à formação para a docência na percepção de licenciandos em Ciências da Natureza/Química do IF-SC/SJ. Dissertação de Mestrado. UFSC. 2015.

SOUTO, N. L. Programa Institucional de Bolsas de Iniciação à Docência (PIBID) e Formação de Professores em Ciências Biológicas: O Programa no IF SULDEMINAS, Campus Inconfidentes. Tese (Doutorado em Educação). Universidade Estadual de Campinas: Faculdade de Educação, UNICAMP, 2018.

TANCREDINI, R. M. S. P. Políticas públicas de formação de professores: o PIBID em foco. Exitus, 3(1): 13-31, 2013.

TARDIF, M. Saberes profissionais dos professores e conhecimentos universitários: elementos para uma epistemologia da prática profissional dos professores e suas consequências em relação à formação para o magistério. Revista Brasileira de Educação, 13: 5-24, 2000. 
TARDIF, M. Saberes docentes e formação profissional. Petrópolis, Vozes, 325p., 2014.

VILELA, M. A biologia na sala de aula pelas escritas de professores em formação: um olhar de pesquisa sobre relatórios de prática de ensino. In: MARANDINO, M. et al. (org.). Ensino de Biologia: histórias, saberes e prática formativas. Uberlândia: EDUFU. p. 89-105, 2009.

\section{NOTAS}

${ }^{1} \mathrm{O}$ modelo $3+1$ é a designação dada para uma estrutura curricular de cursos de licenciatura que a partir do currículo de curso de bacharelado acrescenta-se mais um ano com disciplinas da área de educação para formar um professor em determinada disciplina (GATTI, 2010).

\section{Submetido em 03/11/2017}

Aprovado em 14/07/2018

\section{Contato:}

Faculdade UnB Planaltina (FUP)

Área Universitária N ${ }^{0} 1$

Vila Nossa Senhora de Fátima - Planaltina

CEP: 73.300-000 - Brasília, DF - Brasil 